\title{
Interfaith Spiritual Care: A Systematic Review
}

\author{
Anke I. Liefbroer ${ }^{1} \cdot$ Erik Olsman $^{2,3,4} \cdot$ R. Ruard Ganzevoort ${ }^{1}$ • \\ Faridi S. van Etten-Jamaludin ${ }^{5}$
}

Published online: 15 February 2017

(C) The Author(s) 2017. This article is published with open access at Springerlink.com

\begin{abstract}
Although knowledge on spiritual care provision in an interfaith context is essential for addressing the diversity of patients' religious and spiritual needs, an overview of the literature is lacking. Therefore, this article reviews the empirical literature on interfaith spiritual care (ISC) in professional caring relationships. A systematic search in electronic databases was conducted to identify empirical studies published after 2000. Twenty-two studies were included. The quality of the included studies was assessed, and their results were thematically analyzed. The majority were conducted in North America, mainly using qualitative methods and focusing on professional caregivers, who had a variety of professional and spiritual backgrounds. Two core categories were identified: (1) normativity: reasons for (not) wanting to provide ISC, in which universalist and particularist approaches were identified; and (2) capacity: reasons for (not) being able to provide ISC, which included the competences that health care professionals may need when providing ISC, as well as contextual possibilities and restraints. This systematic review identifies gaps in the literature and indicates that future studies have to explore patient perspectives on ISC.
\end{abstract}

Keywords Interfaith $\cdot$ Spirituality $\cdot$ Religion · Caregivers · Patients · Chaplaincy $\cdot$ Review

Anke I. Liefbroer

a.i.liefbroer@vu.nl

1 Faculty of Theology, VU Amsterdam, De Boelelaan 1105, 1081 HV Amsterdam, The Netherlands

2 Department of General Practice, Section of Medical Ethics, Academic Medical Center, University of Amsterdam, Amsterdam, The Netherlands

3 Department of Neurology, Section of Ethics and Law, Leiden University Medical Center, Leiden, The Netherlands

4 Department of Spiritual Care, Hospice Bardo, Hoofddorp, The Netherlands

5 Medical Library, Academic Medical Center, University of Amsterdam, Amsterdam, The Netherlands 


\section{Introduction}

Over the past decades, the religious and spiritual landscape in Western societies has been transforming rapidly because of processes such as subjectivization, individualization, secularization, globalization, and pluralization (Woodhead et al. 2016). These changes are relevant for the field of spiritual care because they lead to a diversity of spiritual, religious, and cultural needs, which requires professional caregivers to deal with these diverse needs.

Several authors have noted the significance of addressing patients' diverse needs in health care settings (as well as in the military and in penitentiary institutions). Some have provided practical guidelines and recommendations for health care professionals, other than chaplains, on spiritual care for patients of diverse religious traditions (Miklancie 2007; Richards and Bergin 2014; Walsh 2010), and others have plead for an "inter-" or "multifaith" model of spiritual care for spiritual care providers or chaplains (Gatrad et al. 2003, 2004; Schipani and Bueckert 2009). In these discussions, the distinction is often made between an "interfaith," "generic," or "multifaith" approach and a "faith-specific" approach. In the first approach, chaplains are trained to provide spiritual care to patients of all faiths; in the second, chaplains provide care only to those whose faith is similar to their own (Gatrad et al. 2003). In this article, we will use the term "interfaith spiritual care" in a broad sense, indicating a situation wherein caregiver and patient have different spiritual, religious or non-spiritual, or non-religious worldviews. This implies, for example, an Islamic spiritual caregiver and a Christian patient, but it may also imply a situation wherein one has an explicit religious or spiritual orientation and the other has not, such as a Catholic nurse caring for an agnostic patient.

Although an interfaith approach may be one of the ways to provide spiritual care to patients and clients with diverse spiritual needs, the practice of interfaith spiritual care (ISC) has been contested. For example, Fawcett and Noble (2004) hypothesized that, for Christian nurses, providing spiritual care to patients, who hold very different beliefs from their own, may be challenging, especially with regard to maintaining professional and religious integrity. Others noted the limits of an interfaith approach for chaplains with regard to worship with patients of another faith than their own (Gatrad et al. 2003, 2004) or objected to an interfaith approach because they saw it as an extension of a "Protestantbased" chaplaincy model (Abu-Ras and Laird 2011). Additionally, Ganzevoort et al. (2014) point out that the possibility of providing ISC depends on various factors, one of them being the perspectives on spiritual caregiving within the spiritual tradition of the (spiritual) caregiver. The spiritual care model favored in an Islamic perspective differs for example from the spiritual care model favored in a Buddhist perspective, the first using actions such as reciting the Qur'an and advising patients whether certain practices are acceptable or not, and the second being characterized by practicing meditations as a form of contemplative care. These different spiritual care models may pose challenges to providing ISC.

In summary, spiritual care may often operate in encounters where the caregiver and receiver are from different religious or spiritual background, but little is known about the ways in which ISC meets patients' diverse, spiritual needs, and there is debate concerning its practice. To date, an overview of what is actually happening in practices of interfaith spiritual care is lacking. Aiming to provide a starting point in finding that knowledge, the objective of this review was to provide an overview of recurring themes in empirical literature on interfaith spiritual care (ISC) in a professional caring relationship. 


\section{Method}

A systematic review of empirical studies on ISC was conducted (Higgins et al. 2008).

\section{Search Strategy}

On April 2, 2015, we conducted a search, which was updated on January 18, 2016. We searched in the following databases: PsycINFO, EMBASE, Medline, CINAHL, ATLA Religion database, and Philosopher's index. The terms "interfaith," "spiritual," "care," as well as synonyms and closely related words were used. These three terms were combined using the Boolean operator AND.

Articles published before 2000 were excluded. Other exclusion criteria were: not written in English, German, French or Dutch, conference abstracts, editorials, book or article reviews or replies, or missing abstract. Empirical studies were included when they described ISC in a professional caring relationship.

Two researchers screened the titles of the references separately, and then compared and discussed their results, which led to included and excluded references for the next round. In case of doubt, articles were included for the next round. In case of disagreement, a third researcher screened the title and made a final decision. For the title and abstract screening (second round) and the full-text screening (third round), a similar procedure was followed. The cross-references were also screened. For the flow chart, see Fig. 1.

\section{Data Analysis}

Firstly, the characteristics of the included studies were summarized (see Table 1). Secondly, in order to guarantee a minimum of quality of the included studies (Evans 2004), their quality was assessed and a risk of bias was formulated. Since the studies had employed various methodologies, such as in-depth interviews, surveys, and participant observations, different guidelines were used to assess their quality (Tong et al. 2007; Kelley et al. 2003; Leech and Onwuegbuzie 2010). These guidelines provided checklists with items that helped to assess whether the included studies had reported about the items at all (transparency as a first criterion), and if so, what they had reported about these items (validity as a second criterion). Both criteria helped to formulate a risk of bias. More specifically, two researchers formulated a risk of bias independently and, in case of disagreement, discussed their findings until consensus was reached. All included articles were considered to be of sufficient quality, and as a consequence, the results of all studies were used during the next stage.

Thirdly, in order to identify recurring themes that emerged in the data, all included articles were inductively analyzed by the first author, using an iterative process of coding and recoding. These preliminary results were discussed in a research group consisting of three researchers, leading to a classification of themes. 
Databases: PsycINFO, EMBASE, Medline, CINAHL, ATLA Religion database and Philosopher's index consulted 2 April 2015 and 18 January 2016

Strategy:

1. Interfaith (and related terms, e.g. inter-faith, multifaith, inter-relig*)

2. Spiritual (and related terms, e.g. religion, secularism, islam*)

3. Care (and related terms, e.g. chaplain*, patient*, client*)

(1 AND 2 AND 3) OR (1 AND 2) OR (1 AND 3)

PsycINFO (930), EMBASE (1384), Medline (961), CINAHL (274), ATLA Religion database (206) and Philosopher's index (433)

$\mathrm{n}=4188$ (total)

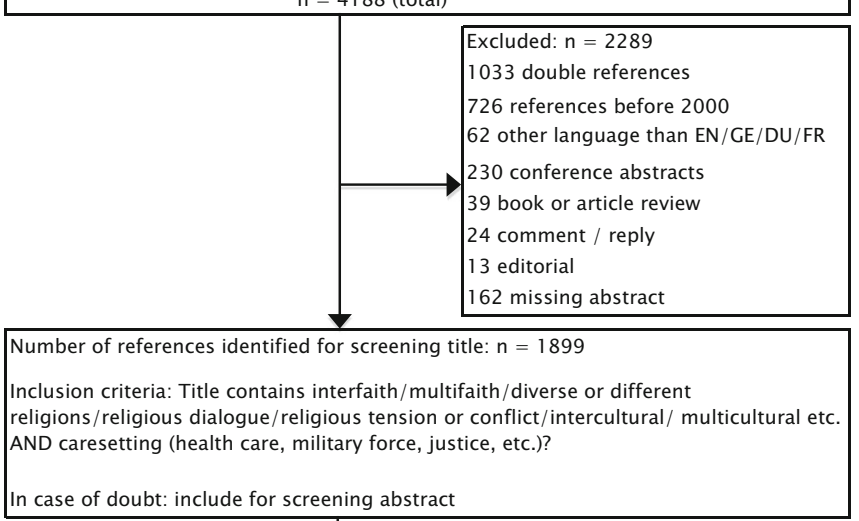

In case of doubt: include for screening abstract

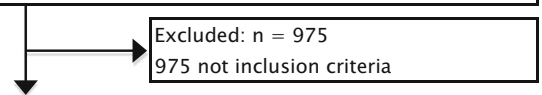

Number of references identified for screening abstract: $n=924$
Inclusion criteria: The article is about interfaith spiritual care in a professional caring
relationship
In case of doubt: include for screening full-text

\begin{tabular}{|l|l|}
\cline { 2 - 3 } & $\begin{array}{l}\text { Excluded: } \mathrm{n}=812 \\
16 \text { on cultural diversity } \\
204 \text { on spiritual care (not interfaith) } \\
63 \text { on moral / ethical dilemma } \\
22 \text { on alternative and complementary } \\
\text { medicine / therapy } \\
507 \text { not inclusion criteria and not on } \\
\text { topics mentioned above }\end{array}$ \\
\hline
\end{tabular}

Number of references identified for screening full-text: $n=112$

Inclusion criteria: The article is about interfaith spiritual care in a professional caring relationship

\begin{tabular}{|l|l|}
\hline Number of references included in the synthesis: $\mathrm{n}=18$ \\
\hline
\end{tabular}

Fig. 1 Flow chart 


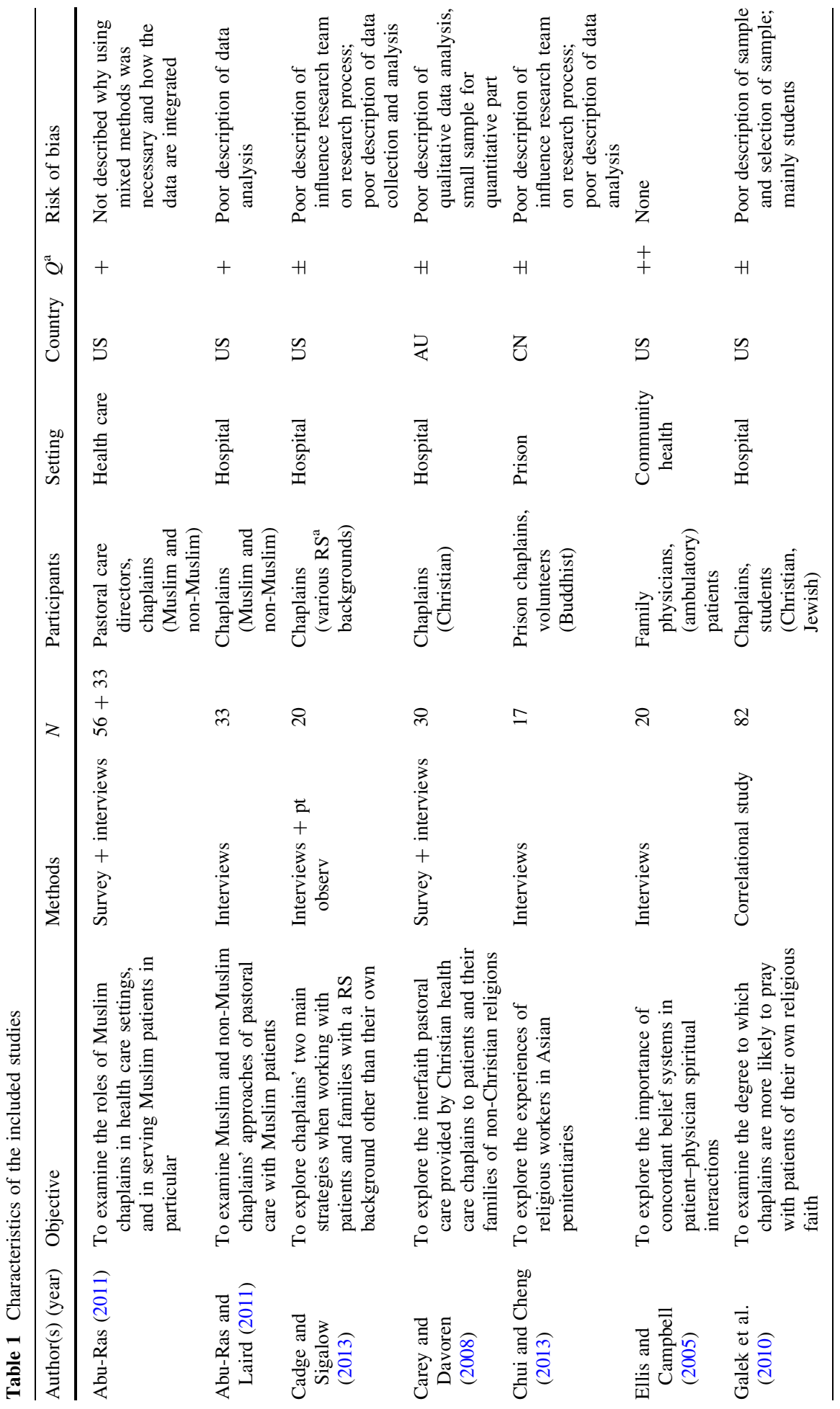




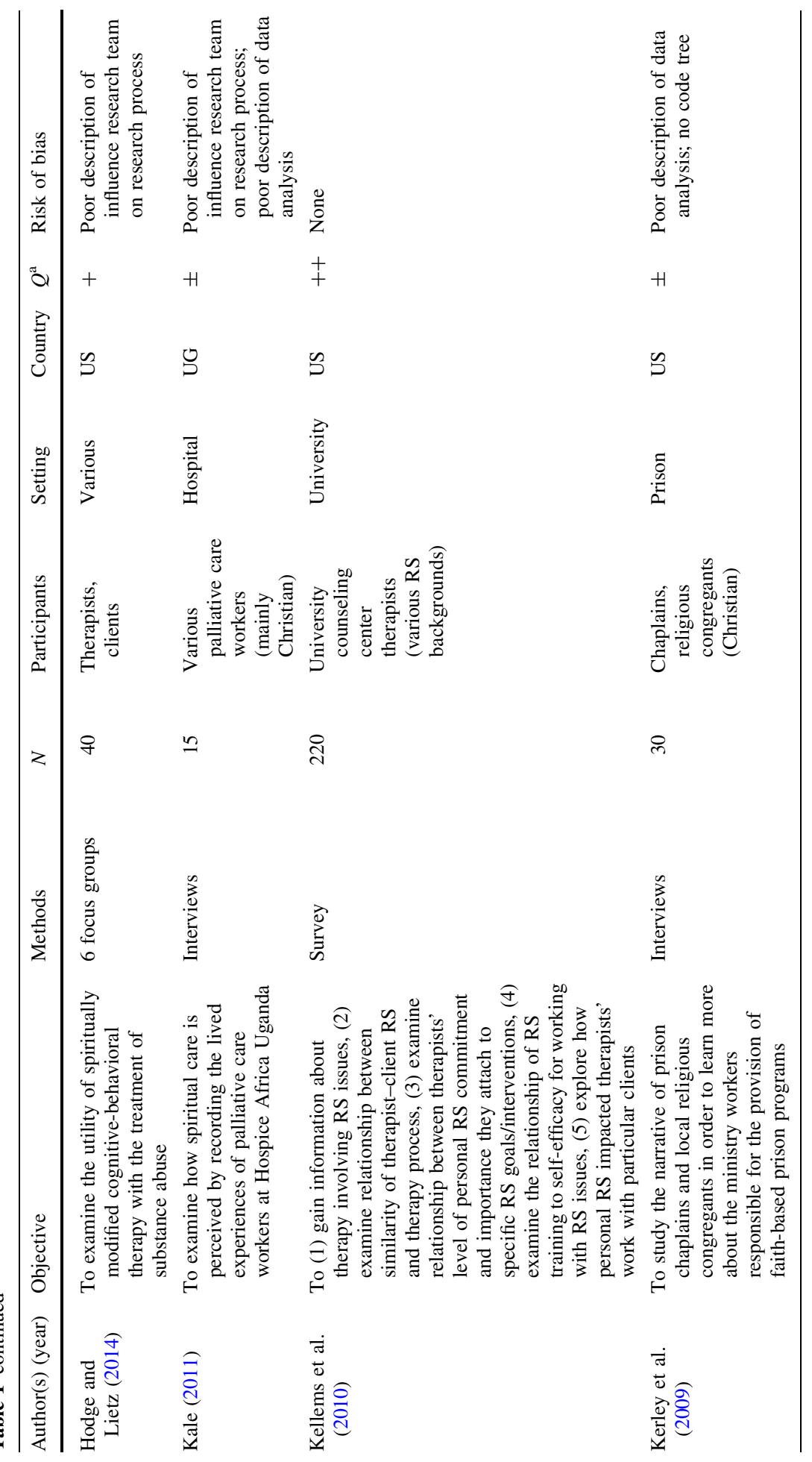




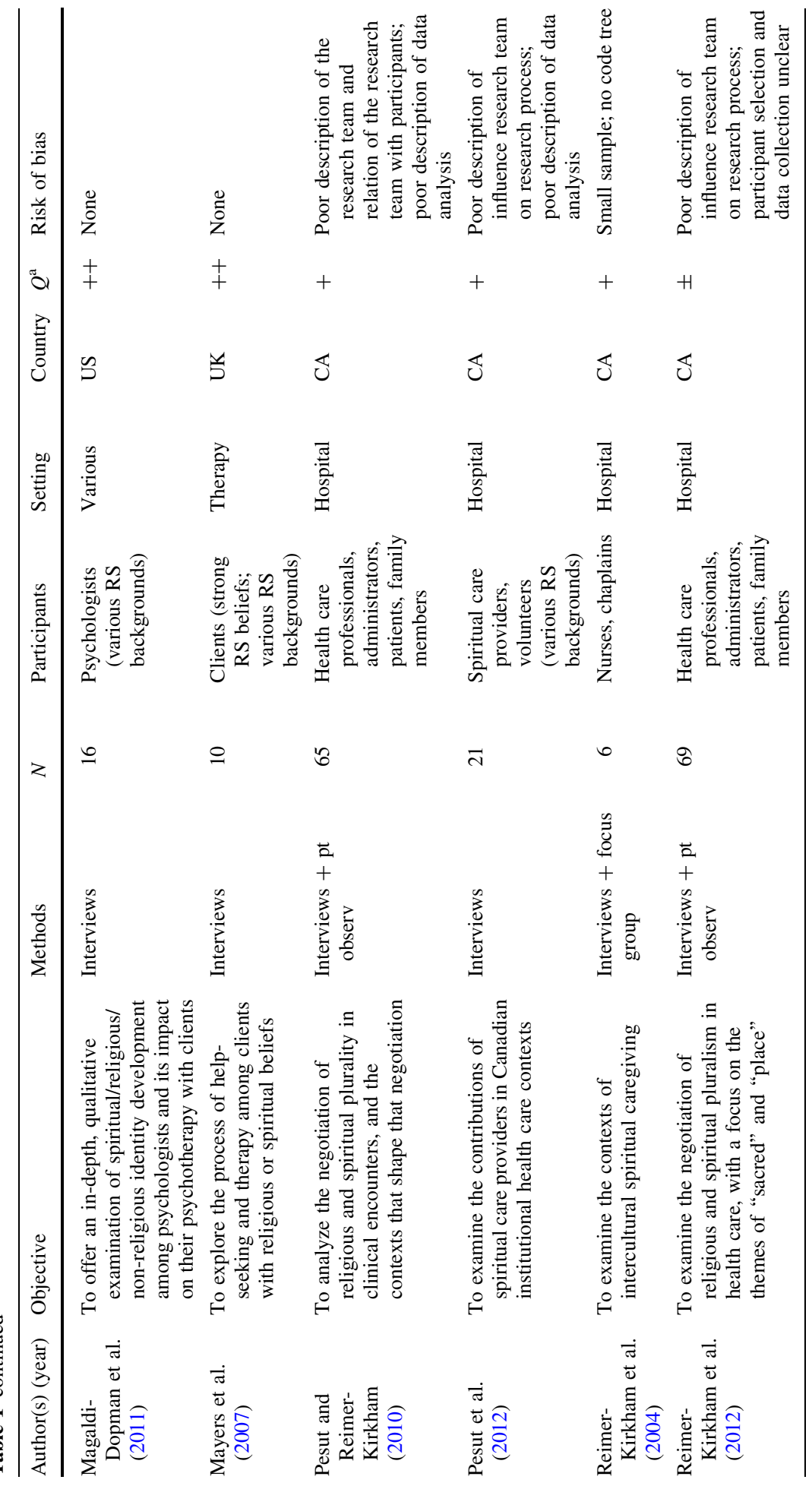




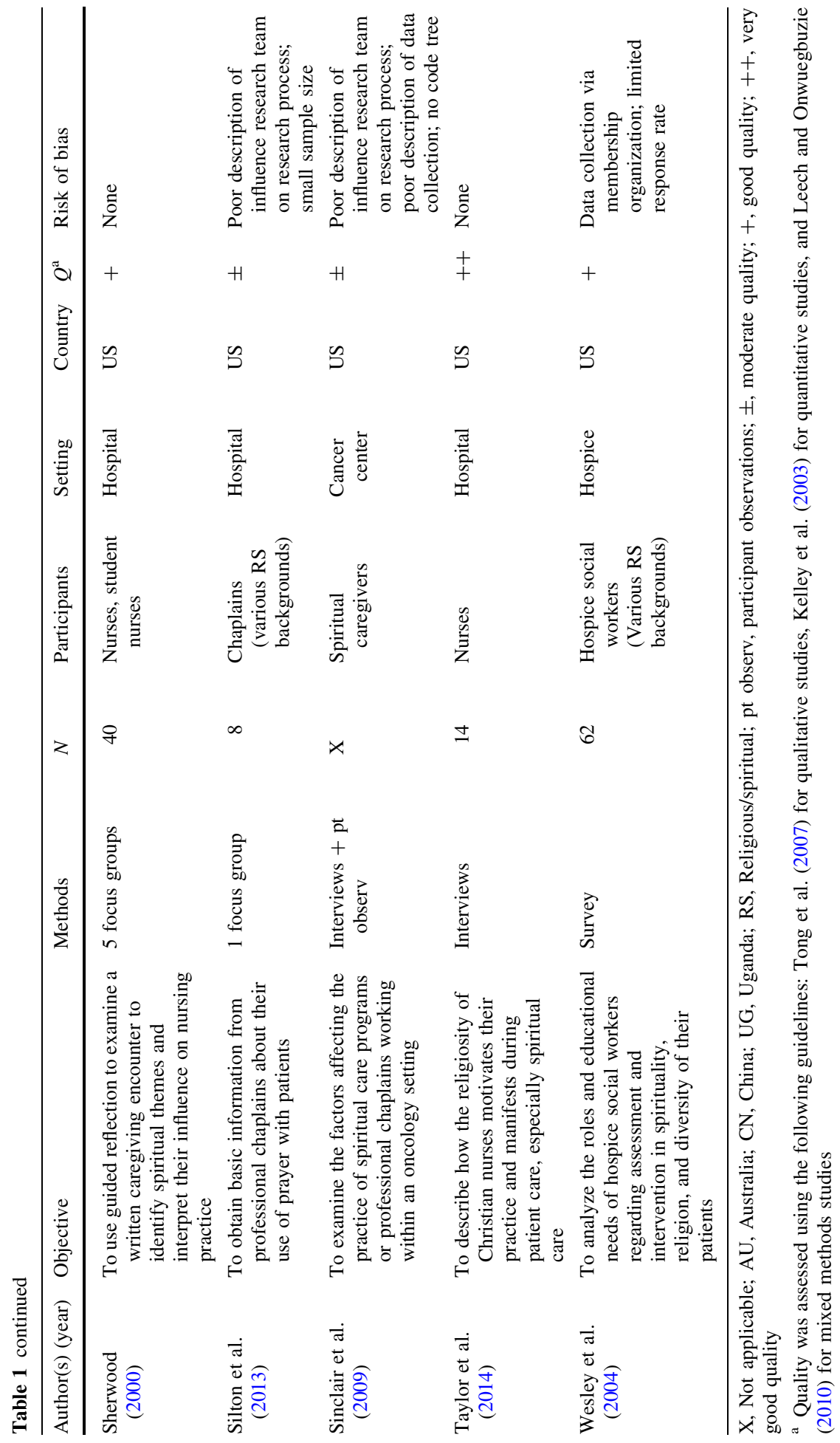




\section{Results}

\section{Characteristics of the Included Articles}

Twenty-two articles were included, of which seventeen qualitative (of which three shared the same database), three quantitative, and two mixed method studies. Seventeen focused exclusively on professionals, the majority studying spiritual care providers, and a minority exploring the perspectives of other professionals, like nurses, physicians, psychologists, social workers, and directors. Four (of which two shared the same database) examined both professionals and patients' or clients' perspectives and one study focused exclusively on clients' perspectives. Participants came from a variety of religious or spiritual backgrounds. Eighteen of the twenty-two included studies had been conducted in the USA or Canada, and most studies had been conducted in health care settings, whereas a few had been conducted in other settings, like prison or university. The majority of the articles were of sufficient or high quality, whereas some of them were of very high quality. For details on the included studies, see Table 1.

\section{Providing Interfaith Spiritual Care: Normativity and Capacity}

The included articles used diverse terms when discussing caregiving to patients of various faiths, such as "concordant and discordant spiritual orientations in physician-patient spiritual discussion" (Ellis and Campbell 2005), "multi-faith chaplaincy," "general prayer" (Pesut et al. 2012), "universal and non-denominational" prayer (Kale 2011) and "interfaith" and a "faith-specific chaplaincy approach" (Abu-Ras and Laird 2011). Not all of those terms were clearly defined.

Nevertheless, recurring themes were identified in the thematic analysis of the included studies, leading to two core categories that were different, yet related: normativity and capacity. Normativity regards an answer to the question: do I want to provide ISC or not, and for which reasons? Capacity implies an answer to the question: is it possible to provide ISC or not, and for which reasons? For a schematic overview of the results, see Tables 2 and 3 .

\section{Normativity}

A difference was found between a universalist approach, favoring ISC, and a particularist approach, mainly opposing ISC. They implied a different (normative) view on identities, relationships, and actions, by answering the following questions in different ways: who do I want to be (identities)? What kind of professional caring relationships do I want to establish (relationships)? And what do I want to do (actions)? A universalist approach implied an identity that was characterized by an open attitude, a caring relationship that was described in terms of spiritual connection, and it implied actions, particularly prayer, which transcended a specific religion. A particularist approach, on the other hand, meant an identity characterized by a visible connection to a particular religion/spirituality, and a caring relationship characterized by the same spiritual background. A particularist approach also included actions that aimed at connecting caregivers and patients with the same spiritual background. Both approaches will be elucidated now. 


\begin{tabular}{|c|c|c|c|}
\hline 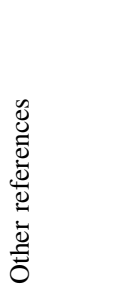 & 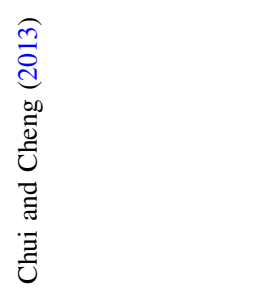 & \multicolumn{2}{|c|}{ 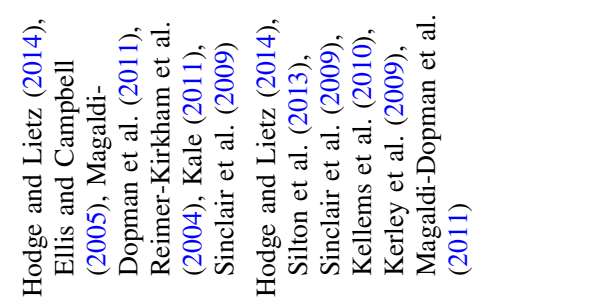 } \\
\hline 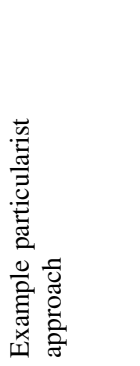 & 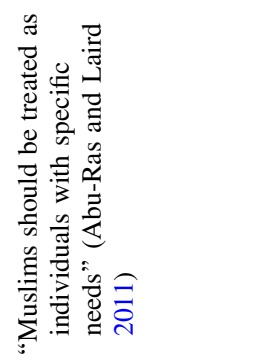 & 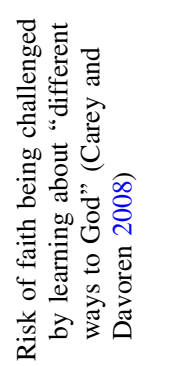 & 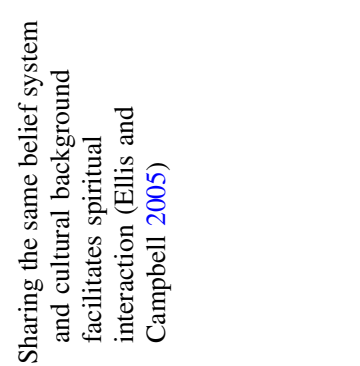 \\
\hline 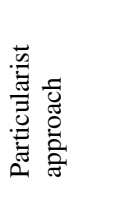 & 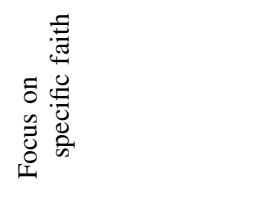 & 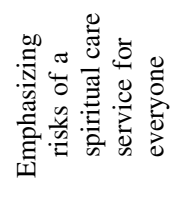 & 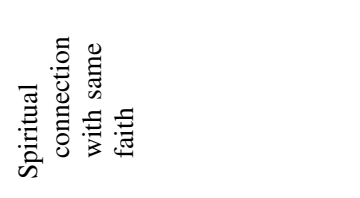 \\
\hline 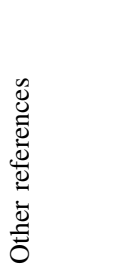 & 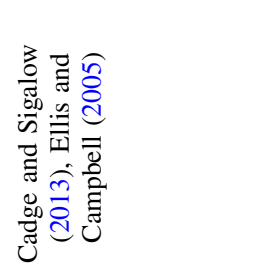 & 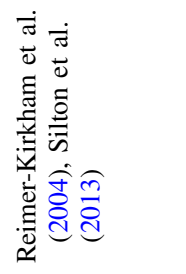 & 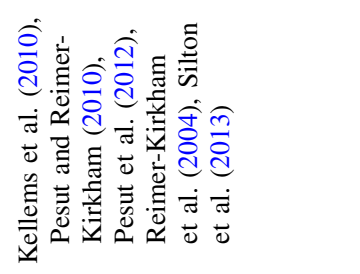 \\
\hline 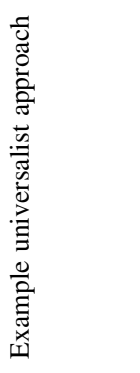 & 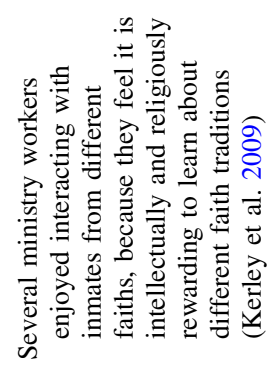 & 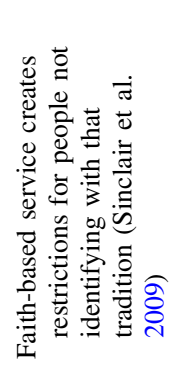 & 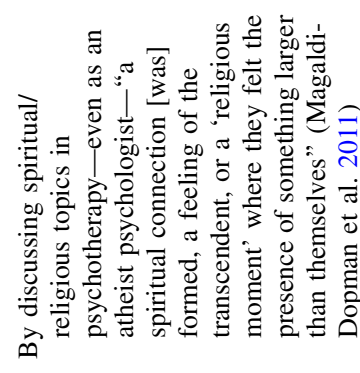 \\
\hline 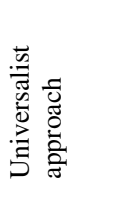 & 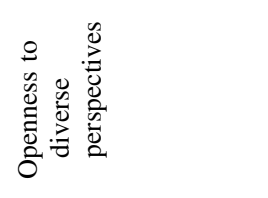 & 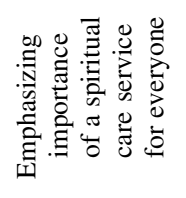 & 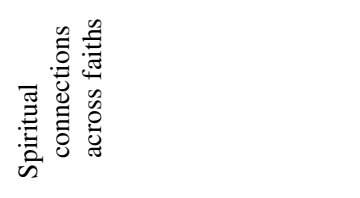 \\
\hline 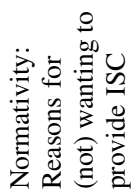 & 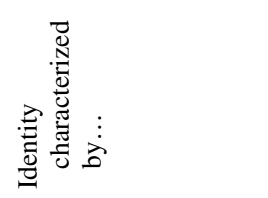 & & 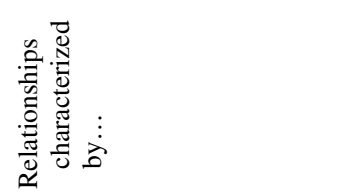 \\
\hline
\end{tabular}




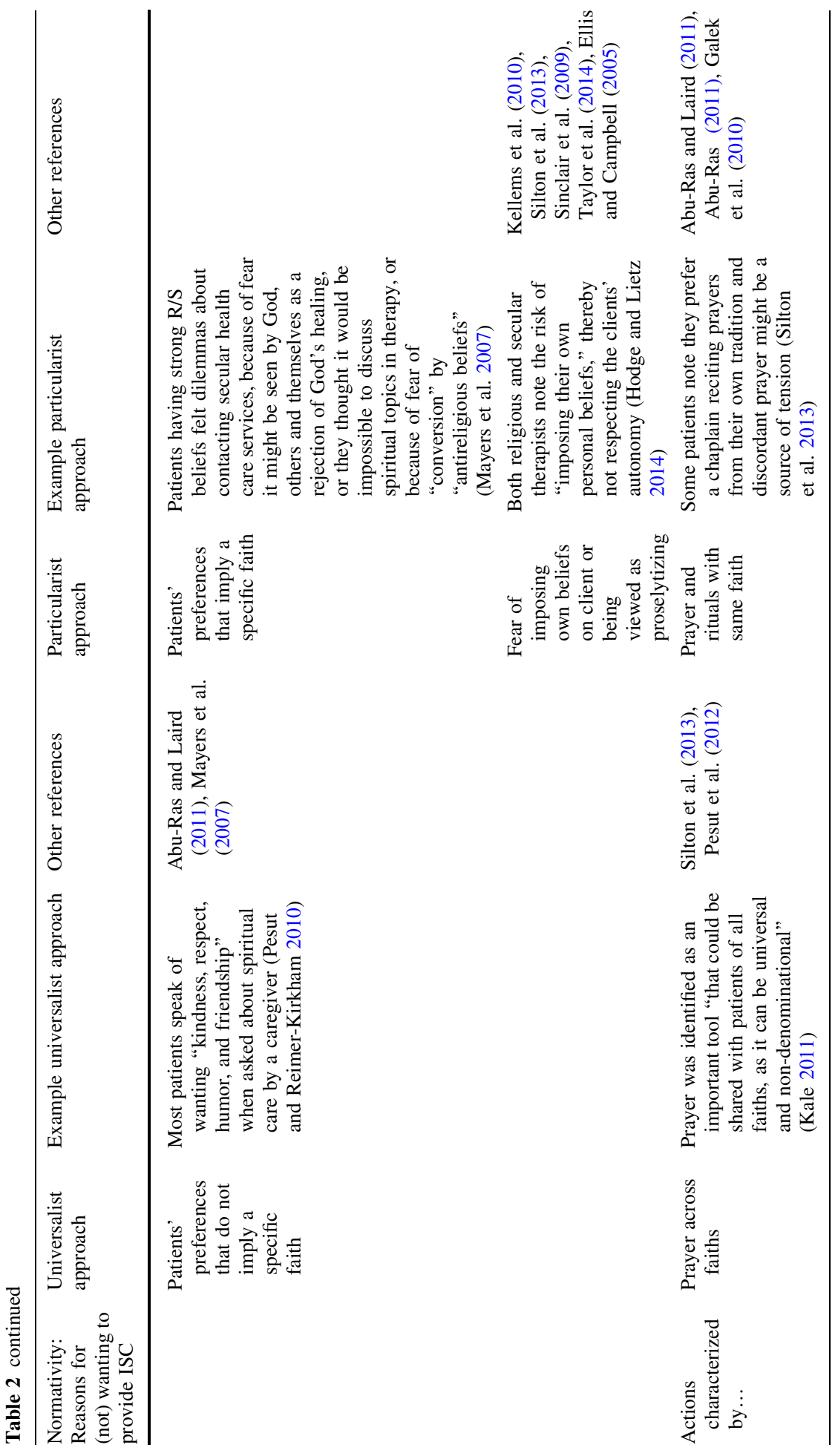


Table 3 Thematic analysis: capacity

\begin{tabular}{|c|c|c|c|}
\hline $\begin{array}{l}\text { Capacity } \\
\text { needed for } \\
\text { providing } \\
\text { ISC }\end{array}$ & Specification & Example & Other references \\
\hline
\end{tabular}

\begin{tabular}{|c|c|c|c|}
\hline \multirow[t]{2}{*}{ Competence } & Strategies & $\begin{array}{l}\text { Being able to neutralize and code- } \\
\text { switch (Cadge and Sigalow 2013); } \\
\text { taking a "patient-centered } \\
\text { viewpoint" (Ellis and Campbell } \\
\text { 2005); using "non-religious } \\
\text { language" when engaging in } \\
\text { conversation with a non-religious } \\
\text { patient (Taylor et al. 2014) }\end{array}$ & $\begin{array}{l}\text { Pesut and Reimer-Kirkham (2010), } \\
\text { Pesut et al. (2012), Abu-Ras and } \\
\text { Laird (2011), Kerley et al. (2009), } \\
\text { Carey and Davoren (2008), } \\
\text { Mayers et al. (2007) }\end{array}$ \\
\hline & $\begin{array}{l}\text { Knowledge/ } \\
\text { recognition }\end{array}$ & $\begin{array}{l}\text { Care providers, when coming from a } \\
\text { different religious/cultural } \\
\text { background than their patients, } \\
\text { might not recognize the } \\
\text { importance of religion/religious } \\
\text { practices for patients (Pesut and } \\
\text { Reimer-Kirkham 2010) }\end{array}$ & $\begin{array}{l}\text { Abu-Ras (2011), Silton et al. } \\
\text { (2013), Ellis and Campbell (2005), } \\
\text { Wesley et al. (2004), Carey and } \\
\text { Davoren (2008), Magaldi-Dopman } \\
\text { et al. (2011) }\end{array}$ \\
\hline \multirow[t]{4}{*}{ Context } & $\begin{array}{l}\text { Individual } \\
\text { level- } \\
\text { possibilities }\end{array}$ & $\begin{array}{l}\text { Patients may experience the visit of } \\
\text { someone of another tradition/ } \\
\text { religion as a privilege or honor } \\
\text { (Silton et al. 2013) }\end{array}$ & None \\
\hline & $\begin{array}{l}\text { Individual } \\
\text { level- } \\
\text { restraints }\end{array}$ & $\begin{array}{l}\text { According to a Catholic chaplain, } \\
\text { when visiting Catholic patients, } \\
\text { "their expectations, and all the } \\
\text { traditions get in the way" (Silton } \\
\text { et al. 2013) }\end{array}$ & $\begin{array}{l}\text { Cadge and Sigalow (2013), Silton } \\
\text { et al. (2013), Kale (2011), Pesut } \\
\text { and Reimer-Kirkham (2010), } \\
\text { Reimer-Kirkham et al. (2004), } \\
\text { Abu-Ras and Laird (2011) }\end{array}$ \\
\hline & $\begin{array}{l}\text { Institutional } \\
\text { level- } \\
\text { possibilities }\end{array}$ & $\begin{array}{l}\text { A faith-based spiritual care service } \\
\text { received no institutional funding, } \\
\text { whereas for those services who } \\
\text { used a non- } \\
\text { denominational/multifaith } \\
\text { approach, it was more likely to } \\
\text { receive monetary support by the } \\
\text { institution (Sinclair et al. 2009) }\end{array}$ & Ellis and Campbell (2005) \\
\hline & $\begin{array}{l}\text { Institutional } \\
\text { level- } \\
\text { restraints }\end{array}$ & None & None \\
\hline
\end{tabular}

Normativity: A universalist approach A universalist approach toward ISC meant in the first place that participants wanted to be open toward other spiritualities because an open attitude facilitated discussions on spiritual topics (Cadge and Sigalow 2013; Ellis and Campbell 2005).

Secondly, participants in several studies described their interfaith caring relationship itself in spiritual terms, like a "wonderful connection" (Silton et al. 2013), "a 'religious moment' where they felt the presence of something larger than themselves" (MagaldiDopman et al. 2011), and a "bond" instead of a "barrier" (Reimer-Kirkham et al. 2004). In addition, in a large survey among university counseling center therapists, the perceived similarity between therapists' and clients' religious or spiritual values was not associated with the strength of the therapeutic relationship (Kellems et al. 2010), and when Pesut and 
Reimer-Kirkham (2010) asked patients $(n=16)$ how they felt about spiritual care by a caregiver, most patients spoke about wanting "kindness, respect, humor, and friendship," not mentioning a particular religious background of their caregiver. Most non-Muslim chaplains in another study (Abu-Ras and Laird 2011) suggested that Muslim patients often do not need an imam (or a substitute in their absence) because, for example, they are secularized or their needs will be met another way.

Thirdly, a universalist approach implied universal actions, and prayer was mentioned frequently. Participants in two studies noted the beauty of multifaith or "general" prayer (Pesut et al. 2012; Silton et al. 2013), and a study conducted in Uganda (Kale 2011) found that interfaith "prayer was considered a very important tool that could be shared with patients of all faiths, as it can be universal and non-denominational."

Normativity: a particularist approach Other findings supported a particularist approach, mainly favoring faith-based spiritual care. For example, several chaplains in one study (Abu-Ras and Laird 2011) noted the importance of treating patients as individuals with specific needs, who might best be cared for by someone of the same religious background. Sinclair et al. (2009), in addition, found that a multifaith spiritual care model was perceived by some chaplains as a "diluted form of spiritual care," suggesting they may be afraid of losing the particularity of their own (spiritual) identity. According to more than half of the included thirty Christian chaplains in another study, learning about "different ways to God" challenged their own faith (Carey and Davoren 2008).

A particularist approach was also supported by studies that reported difficulties in relationships and interactions when patients and caregivers had different beliefs (Ellis and Campbell 2005; Magaldi-Dopman et al. 2011; Reimer-Kirkham et al. 2004; Taylor et al. 2014; Kerley et al. 2009). For example, some caregivers were hesitant to provide ISC because they feared being viewed as proselytizing or imposing their own beliefs on patients, thereby not respecting patients' autonomy (Silton et al. 2013; Hodge and Lietz 2014). Sharing the same belief system, in addition, facilitated spiritual interaction (Ellis and Campbell 2005), brought confidence and comfort (Ellis and Campbell 2005; Silton et al. 2013), served as a "point of unity" (Sinclair et al. 2009), and facilitated social support (Hodge and Lietz 2014). Silton et al. (2013) provided another example favoring a particularist approach: they found that discordant prayer-praying with someone of a different faith — might be a source of tension, and patients in their study preferred a chaplain reciting prayers from their own tradition.

In terms of actions, a particularist approach aimed to connect caregivers and patients with the same spiritual background. Abu-Ras and Laird (2011) reported, for instance, how a chaplain referred patients requesting a religious ritual to a chaplain with the same spiritual background. In addition, chaplains in another study were more likely to pray with people from the same religion than with patients who adhered to a different religion (Galek et al. 2010).

\section{Capacity}

The capacity to provide ISC included health care professionals' competences, and the possibilities and restraints of the context in which ISC was provided. Health care professionals needed the capacity to create a third space, in-between two spiritual worlds/ discourses, and knowledge of other spiritualities was required. Contextual restraints and possibilities, included, among other things, the name "chaplain" and her/his denomination, 
and health care institutions favoring ISC instead of faith-based approaches. The capacity to provide ISC will be described in detail now.

Capacity: competence Some of the included studies identified strategies caregivers used to provide ISC, and they seemed to assume the capacity to create a third, relational space, in-between two discourses or worlds. Cadge and Sigalow (2013), for instance, noted the ability of "neutralizing" (emphasizing commonalities) and "code-switching" (moving between different religious languages, symbols, and practices). The notion of focusing on similarities between various beliefs by volunteers and chaplains in the study of Kerley et al. (2009) also reflected their ability to "neutralize." In a similar vein, Pesut and ReimerKirkham (2010) spoke about eliciting patients' meaning systems "as a means to transcend difference and create safe sacred spaces" and, in another study by Pesut et al. (2012), about spiritual care providers creating "sacred, inclusive spaces and language." Within this relational space, the importance of focusing on the patients' perspective was mentioned frequently in the included studies. Ellis and Campbell (2005) noted for instance that, according to physicians as well as patients, taking a "patient-centered viewpoint" is one of the approaches physicians need when engaging in conversation with patients holding different beliefs. Likewise, Taylor et al. (2014) mentioned the use of "non-religious language" when engaging, as a Christian nurse, in conversation with a non-religious patient. Mayers et al. (2007) reported that "acceptance, respect, understanding and then a willingness to work with, and not against, the participant's way of viewing the problem and ideas about a solution enhanced the development of a sound therapeutic relationship."

In addition to this relational space, several studies suggested that knowledge of other spiritualities reinforced the capacity to provide ISC, and a lack of this knowledge hindered ISC (Wesley et al. 2004; Carey and Davoren 2008). Others found that health care professionals, when coming from a different religious or cultural background than their patients, may not have the capacity to recognize the importance of spirituality for patients or diagnose their spiritual needs (Pesut and Reimer-Kirkham 2010; Abu-Ras 2011). The study of Magaldi-Dopman et al. (2011) forms an exception: they found that atheist and agnostic psychologists were more likely than psychologists with a religious or spiritual background to "pay close attention to religious issues in psychotherapy because they were afraid to overlook this area because of their own beliefs." Thus, whereas some authors reported the lack of knowledge and recognition of various spiritualities created barriers to ISC, fear of not being able to recognize the role of certain beliefs may also create an incentive to attend to those topics.

Capacity: context Besides the individual competences of health care professionals, there were also contextual possibilities and restraints that shaped the capacity for providing ISC. Most of these were reported in chaplaincy studies. At the individual level, several included studies reported impediments to providing ISC, like language differences (Kale 2011; Pesut and Reimer-Kirkham 2010; Reimer-Kirkham et al. 2004), gender issues, such as rejection when visiting someone of the opposite sex (Pesut and Reimer-Kirkham 2010; Abu-Ras and Laird 2011), and politics (Abu-Ras and Laird 2011). Another restraint was the name "chaplain" and the denomination of the chaplain. A Jewish and a Muslim chaplain, in one study, for example mentioned that the Christian connotation of the term "chaplaincy" sometimes made Jewish or Muslim patients reject spiritual care (Cadge and Sigalow 2013). In addition, Silton et al. (2013) reported that there seemed to be confusion concerning the name "chaplain," especially for Muslim and Jewish patients, and that 
Jewish patients sometimes asked for a "rabbi" instead of a (multifaith) chaplain because they were unfamiliar with the term "chaplaincy." However, they also described that the denomination of the chaplain might offer possibilities. A Catholic chaplain in their study explained that, when visiting Jewish patients, these patients experienced this as a privilege or honor, while when visiting Catholic patients, "their expectations, and all the traditions get in the way."

At the institutional level, only possibilities for providing ISC were mentioned, mainly reported by Sinclair et al. (2009). They noted, for instance, that a spiritual care service that "understood its mandate as tending to the spiritual needs of the diverse clientele of its institution was more likely to be recognized as a formal service by health care staff (...)." At one of the sites, visited by the same researchers, the faith-based spiritual care service received no institutional funding because it was "identified by administration as a representative of their faith-based institution rather than a professional attending to an important aspect of universal human health." Furthermore, spiritual care services that used a nondenominational and multifaith approach were more likely to receive institutional funding.

\section{Discussion}

This review provides an overview of twenty-two empirical studies on interfaith spiritual care (ISC) in a professional caring relationship, suggesting that there are (at least) two categories involved in ISC: normativity and capacity. The first category-normativitymeans the reasons for (not) wanting to provide ISC, consisting of a universalist and particularist approach. The second category—capacity—consists of reasons for (not) being able to provide ISC, which included competences needed to provide ISC and contextual possibilities and restraints.

The first category, normativity, relates to the legitimacy of ISC. Firstly, from the perspective of certain spiritual traditions such as Christian ones, it is important to care for everyone (Schipani and Bueckert 2009), which may (partly) support a universalist approach. In addition, from an organizational or institutional perspective ISC appears to be legitimate, as it fits the aim of national health services to care for patients regardless of their religious background (National Health Service 2015) and because it is more likely to receive funding (Sinclair et al. 2009). ISC may be legitimate from the perspective of patients as well. Some of the results in this review study suggest that, according to patients, the caregivers' religious orientation does not play a major role in spiritual caregiving, although it may be important for a minority group (Abu-Ras and Laird 2011; Pesut and Reimer-Kirkham 2010). However, no definitive conclusions can be drawn from the limited research conducted thus far, and future research should further explore the legitimacy of ISC.

The second category - capacity — highlights important competences required to provide ISC, for example code-switching and neutralizing (Cadge and Sigalow 2013). However, we should ask how reasonable it is to expect from (spiritual) caregivers that they have indepth knowledge of all spiritual traditions. Moreover, this review suggests that there are contextual restraints that hinder ISC, and therefore training of competences may only be one condition for providing good ISC. Thirdly, the included studies have mainly described prayer and (verbal) communication on spiritual issues, which reflects a view on spiritual care that prevails in Protestant Christianity but is less central to other spiritual traditions such as Islam (Abu-Ras and Laird 2011), Buddhism, or neo-paganism. A broader concept 
of spiritual care should include the performance of rituals, meditations, education, and advice-giving (Ganzevoort et al. 2014). Further research on these various dimensions of ISC is necessary.

Although this review demonstrates that some initial research has been conducted on the topic of ISC, there still seem to be several gaps in the literature on this issue, as illustrated by the limitations of the included studies in this review. First, the number of empirical studies identified is small (twenty-two), and the data gathered in these studies are limited because of small sample sizes. As a consequence, we should be cautious in generalizing the findings of these studies. In qualitative meta-analysis, however, the aim is not statistical generalization but theory-building through transferability. The insights thus may be considered to be transferable rather than generalizable.

Secondly, the majority of the included studies were conducted in the USA and Canada, which is in line with the findings of a recent review study on chaplaincy research at large (Pesut et al. 2016). Since the religious and spiritual landscape in North America differs from other Western societies, for instance Europe (Berger et al. 2008), and even more from non-Western societies, future research should also be conducted in other cultural contexts.

Since most of the included studies used self-report approaches to investigate ISC, the way ISC encounters actually take place have hardly been explored. Moreover, the included articles in this review study mainly focused on professional caregivers' perceptions, and only five of them have examined clients' or patients' perspectives. This limitation necessitates the exploration of patient perspectives on ISC in future studies.

This study identified various terms that were used describing approaches to care for patients of diverse spiritual or religious backgrounds. Since this terminology varies widely and sometimes lacks a clear definition and conceptual framework, not only more research has to be done to investigate practices of ISC, but also to explore its theoretical assumptions.

One of the strengths of this systematic review is that it provides insight into some key issues in ISC. In addition, it shows the current state of affairs with respect to research on ISC by providing an overview of what is already investigated (and what is not) in empirical research on this topic.

\section{Conclusion}

The knowledge gained through this systematic review helps to understand some key issues in interfaith spiritual care (ISC) within a landscape characterized by a diversity of spiritual needs. It provides an overview of what is known regarding ISC and identifies gaps in the literature. It indicates, for instance, that future studies should investigate what ISC encounters actually look like in practice, and that future studies should explore patients' perspectives on ISC, in order to learn how ISC contributes to patients' spiritual wellbeing. Our hope is that these future studies, together with the results presented in this review study, will contribute to good spiritual care that attunes to patients and their family members with a diversity of spiritual needs and backgrounds.

Acknowledgements The authors would like to express their thanks to Eline Minnaar for her contribution to this study.

\section{Compliance with Ethical Standards}

Conflict of interest The authors declare that they have no conflict of interest. 
Human and Animal Rights This article does not contain any studies with human participants or animals performed by any of the authors.

Open Access This article is distributed under the terms of the Creative Commons Attribution 4.0 International License (http://creativecommons.org/licenses/by/4.0/), which permits unrestricted use, distribution, and reproduction in any medium, provided you give appropriate credit to the original author(s) and the source, provide a link to the Creative Commons license, and indicate if changes were made.

\section{References}

The included studies in this review are marked with an asterisk.

*Abu-Ras, W. (2011). Muslim chaplain's role as perceived by directors and chaplains of New York City hospitals and health care settings. Journal of Muslim Mental Health, 6(1), 21-43.

*Abu-Ras, W., \& Laird, L. (2011). How Muslim and non-Muslim chaplains serve Muslim patients? Does the interfaith chaplaincy model have room for Muslims' experiences? Journal of Religion and Health, 50(1), 46-61. doi:10.1007/s10943-010-9357-4.

Berger, P. L., Davie, G., \& Fokas, E. (2008). Religious America, secular Europe? A theme and variation. Aldershot: Ashgate.

*Cadge, W., \& Sigalow, E. (2013). Negotiating religious differences: The strategies of interfaith chaplains in healthcare. Journal for the Scientific Study of Religion, 52(1), 146-158. doi:10.1111/jssr.12008.

*Carey, L. B., \& Davoren, R. P. (2008). Inter-faith pastoral care and the role of the health care chaplain. Scottish Journal of Healthcare Chaplaincy, 11(1), 21-32.

*Chui, W. H., \& Cheng, K. K.-Y. (2013). Self-perceived role and function of Christian prison chaplains and Buddhist volunteers in Hong Kong prisons. International Journal of Offender Therapy and Comparative Criminology, 57(2), 154-168. doi:10.1177/0306624X11432128.

*Ellis, M. R., \& Campbell, J. D. (2005). Concordant spiritual orientations as a factor in physician-patient spiritual discussions: A qualitative study. Journal of Religion and Health, 44(1), 39-53. doi:10.1007/ s10943-004-1144-7.

Evans, D. (2004). The systematic review report. Collegian, 11(2), 8-11.

Fawcett, T. N., \& Noble, A. (2004). The challenge of spiritual care in a multi-faith society experienced as a Christian nurse. Journal of Clinical Nursing, 13(2), 136-142.

*Galek, K., Silton, N. R., Vanderwerker, L. C., Handzo, G. F., Porter, M., Montonye, M. G., et al. (2010). To pray or not to pray: Considering gender and religious concordance in praying with the ill. Journal of Health Care Chaplaincy, 16(1-2), 42-52. doi:10.1080/08854720903529694.

Ganzevoort, R. R., Ajouaou, M., Van der Braak, A., de Jongh, E., \& Minnema, L. (2014). Teaching spiritual care in an interfaith context. Journal for the Academic Study of Religion, 27(2), 178-197. doi:10.1558/ jasr.v27i2.178.

Gatrad, A. R., Brown, E., \& Sheikh, A. (2004). Developing multi-faith chaplaincy. Archives of Disease in Childhood, 89(6), 504-505.

Gatrad, A. R., Sadiq, R., \& Sheikh, A. (2003). Multifaith chaplaincy. Lancet, 362(9385), 748.

Higgins, J. P. T., Green, S., \& Cochrane Collaboration. (2008). Cochrane handbook for systematic reviews of interventions. Chichester: Wiley-Blackwell.

*Hodge, D. R., \& Lietz, C. A. (2014). Using spiritually modified cognitive-behavioral therapy in substance dependence treatment: therapists' and clients' perceptions of the presumed benefits and limitations. Health and Social Work, 39(4), 200-210.

*Kale, S. S. (2011). Perspectives on spiritual care at Hospice Africa Uganda. International Journal of Palliative Nursing, 17(4), 177-182.

*Kellems, I. S., Hill, C. E., Crook-Lyon, R. E., \& Freitas, G. (2010). Working with clients who have religious/spiritual issues: A survey of university counseling center therapists. Journal of College Student Psychotherapy, 24(2), 139-155. doi:10.1080/87568220903558745.

Kelley, K., Clark, B., Brown, V., \& Sitzia, J. (2003). Good practice in the conduct and reporting of survey research. International Journal for Quality in Health Care, 15(3), 261-266. doi:10.1093/intqhe/ $\operatorname{mzg} 031$.

*Kerley, K. R., Matthews, T. L., \& Shoemaker, J. (2009). A simple plan, a simple faith: Chaplains and lay ministers in Mississippi prisons. Review of Religious Research, 51(1), 87-103.

Leech, N. L., \& Onwuegbuzie, A. I. (2010). Guidelines for conducting and reporting mixed research in the field of counseling and beyond. Journal of Counseling and Development, 88(1), 61-69. 
*Magaldi-Dopman, D., Park-Taylor, J., \& Ponterotto, J. G. (2011). Psychotherapists' spiritual, religious, atheist or agnostic identity and their practice of psychotherapy: A grounded theory study. Psychotherapy Research, 21(3), 286-303. doi:10.1080/10503307.2011.565488.

*Mayers, C., Leavey, G., Vallianatou, C., \& Barker, C. (2007). How clients with religious or spiritual beliefs experience psychological help-seeking and therapy: A qualitative study. Clinical Psychology \& Psychotherapy, 14(4), 317-327. doi:10.1002/cpp.542.

Miklancie, M. A. (2007). Caring for patients of diverse religious traditions: Islam, a way of life for Muslims. Home Healthcare Nurse, 25(6), 413-417. doi:10.1097/01.NHH.0000277692.11916.f3.

National Health Service. (2015). NHS chaplaincy guidelines 2015. Promoting excellence in pastoral, spiritual \& religious care. http://webarchive.nationalarchives.gov.uk/20150505155840/http://www. england.nhs.uk/wp-content/uploads/2015/03/nhs-chaplaincy-guidelines-2015.pdf. Accessed March 22, 2016.

Pesut, B., \& Reimer-Kirkham, S. (2010). Situated clinical encounters in the negotiation of religious and spiritual plurality: a critical ethnography. International Journal of Nursing Studies, 47(7), 815-825.

*Pesut, B., Reimer-Kirkham, S., Sawatzky, R., Woodland, G., \& Peverall, P. (2012). Hospitable hospitals in a diverse society: From chaplains to spiritual care providers. Journal of Religion and Health, 51(3), 825-836. doi:10.1007/s10943-010-9392-1.

Pesut, B., Sinclair, S., Fitchett, G., Greig, M., \& Koss, S. E. (2016). Health care chaplaincy: A scoping review of the evidence 2009-2014. Journal of Health Care Chaplaincy, 22(2), 67-84. doi:10.1080/ 08854726.2015.1133185.

*Reimer-Kirkham, S., Pesut, B., Meyerhoff, H., \& Sawatzky, R. (2004). Spiritual caregiving at the juncture of religion, culture, and state. CJNR. Canadian Journal of Nursing Research, 36(4), 148-169.

*Reimer-Kirkham, S., Sharma, S., Pesut, B., Sawatzky, R., Meyerhoff, H., \& Cochrane, M. (2012). Sacred spaces in public places: Religious and spiritual plurality in health care. Nursing Inquiry, 19(3), 202-212. doi:10.1111/j.1440-1800.2011.00571.x.

Richards, P. S., \& Bergin, A. E. (2014). Handbook of psychotherapy and religious diversity (2nd ed.). Washington, DC: American Psychological Association.

Schipani, D. S., \& Bueckert, L. D. (2009). Interfaith spiritual care understandings and practices. Kitchener, ON: Pandora Press.

*Sherwood, G. D. (2000). The power of nurse-client encounters. Interpreting spiritual themes. Journal of Holistic Nursing, 18(2), 159-175.

*Silton, N. R., Flannelly, K. J., Galek, K., \& Fleenor, D. (2013). Pray tell: The who, what, why, and how of prayer across multiple faiths. Pastoral Psychology, 62(1), 41-52. doi:10.1007/s11089-012-0481-9.

*Sinclair, S., Mysak, M., \& Hagen, N. A. (2009). What are the core elements of oncology spiritual care programs? Palliative and Supportive Care, 7(4), 415-422. doi:10.1017/S1478951509990423.

*Taylor, E. J., Park, C. G., \& Pfeiffer, J. B. (2014). Nurse religiosity and spiritual care. Journal of Advanced Nursing, 70(11), 2612-2621. doi:10.1111/jan.12446.

Tong, A., Sainsbury, P., \& Craig, J. (2007). Consolidated criteria for reporting qualitative research (COREQ): A 32-item checklist for interviews and focus groups. International Journal for Quality in Health Care, 19(6), 349-357. doi:10.1093/intqhe/mzm042.

Walsh, F. (2010). Spiritual diversity: Multifaith perspectives in family therapy. Family Process, 49(3), 330-348. doi:10.1111/j.1545-5300.2010.01326.x.

*Wesley, C., Tunney, K., \& Duncan, E. (2004). Educational needs of hospice social workers: Spiritual assessment and interventions with diverse populations. The American Journal of Hospice \& Palliative Care, 21(1), 40-46.

Woodhead, L., Partridge, C. H., \& Kawanami, H. (2016). Religions in the modern world: Traditions and transformations (3rd ed.). New York, NY: Routledge. 